\title{
EFEITO DO NIM (AZADIRACHTA INDICA) NA MOSCA-DAS-FRUTAS CERATITIS CAPITATA (DIPTERA: TEPHRITIDAE) E SEU PARASITOIDE DIACHASMIMORPHA LONGICAUDATA (HYMENOPTERA: BRACONIDAE)
}

\section{W.M. França ${ }^{1}$, C.D. Alvarenga ${ }^{1}$, T.A. Giustolin ${ }^{1}$, P.R. Oliveira ${ }^{1}$, P.L. Cruz $^{1}$, G.N. Lopes ${ }^{1}$, B.A.J. Paranhos ${ }^{2}$}

${ }^{1}$ Universidade Estadual de Montes Claros, Departamento deCiências Agrárias, Rua Reinaldo Viana, 2630,CEP 39440-000, Janaúba, MG, Brasil. E-mail: leymota@bol.com.br

\section{RESUMO}

Este trabalho teve como objetivo avaliar a ação do inseticida botânico nim em larvas de Ceratitis capitata, bem como no parasitismo destas larvas por Diachasmimorpha longicaudata. Para tanto, larvas de $3^{\circ}$ ínstar de C. capitata foram mergulhadas por 30 segundos em soluções contendo as concentrações de $0,5 \%, 1 \%$ e 1,5\% de um produto comercial à base de óleo de nim a 0,37\% (3.686 ppm), além da testemunha mergulhada apenas em água destilada. Em seguida, as larvas foram expostas ao parasitismo de $D$. longicaudata por um período de 2 horas e 30 minutos. No experimento sem chance de escolha, para cada tratamento, uma única "unidade de parasitismo" foi pendurada no interior da gaiola. No experimento com livre escolha, as "unidades de parasitismo" foram penduradas no interior de uma mesma gaiola, de forma que os parasitoides tivessem livre acesso a todos os tratamentos. No experimento sem livre escolha, foi constatado que o aumento da concentração de nim diminuiu a atração das fêmeas, o número de fêmeas que efetuaram postura, o índice de parasitismo e a emergência dos parasitoides. No experimento com livre escolha, verificou-se que a emergência dos parasitoides e o índice de parasitismo também foram prejudicados nas maiores concentrações de nim. A ação isolada do nim, quando em contato com as larvas de $3^{\circ}$ instar, não afetou a emergência de C. capitata.

PALAVRAS-CHAVE: Ceratitis capitata, repelência, azadiractina, parasitismo.

\section{ABSTRACT}

EFFECTOFNEEM(AZADIRACHTA INDICA)OILON THE FRUIT-FLY CERATITIS CAPITATA (DIPTERA: TEPHRITIDAE) AND ITS PARASITOID DIACHASMIMORPHA LONGICAUDATA (HYMENOPTERA: BRACONIDAE). The purpose of this work was to evaluate the action of the botanic insecticide neem oil on larvae of Ceratitis capitata, as well as in the parasitism of these larvae by Diachasmimorpha longicaudata. Third-instar larvae were immersed for 30 seconds in a neem solution, in concentrations of $0.5 \%, 1 \%$ and $1.5 \%$ of a commercial product composed of $0.37 \%(3.686$ ppm) neem oil, while the controls were immersed only in distilled water. Soon afterwards the larvae were exposed to parasitism of $D$. longicaudata for 2 hours and 30 minutes. In the no-choice experiment, for every treatment, a single "parasitism unit" was hung inside the cage. In the experiment with free choice, "parasitism units" were hung inside another cage, so that the parasitoids had free access to all treatments. In the no-choice experiment, it was ascertained that the increase of the neem oil concentration decreased the attraction of the females, the number of females that lay, the parasitism rate and parasitoid emergency. In the experiment with free choice, it was ascertained that the emergence of parasitoids and parasitism rate were harmed at the larger neem oil concentrations. The isolated action of neem oil, when in contact with the third-instar larvae, did not affect the emergence of $C$. capitata.

KEY WORDS: Ceratitis capitata, repellency, azadirachtin, parasitism.

\section{INTRODUÇÃO}

As moscas-das-frutas (Diptera: Tephritidae) são consideradas as principais pragas da fruticultura mundial (Hickel, 2002) e um dos entraves para a exportação defrutas. A incidência dessas moscaséum fator de preocupação, acarretando aumentos nos custos de produçãoem razão das frequentes aplicações de

${ }^{2}$ Embrapa Semiárido, Petrolina, PE, Brasil. 
inseticidas para seu controle e perdas na produção, sendodegrandeimportâncianãosópelos danos diretos que causam às frutas, como também pela limitação às exportações devido às restrições quarentenárias (NORA et al., 2000; BITTENCOURT et al., 2006).

A densidade populacional das moscas-das-frutas está diretamente relacionada com a disponibilidade de frutos de seus hospedeiros (NASCIMENTO; CARVALHO, 2000; CARVALHO, 2003), fato este que dificulta em muito o controle, já que as moscas possuem uma vasta gama de hospedeiros, que são muitas vezes nativos. Esses hospedeiros proporcionam maiores condições de sobrevivência aos tefritídeos durante todo o ano, podendo inclusive ocorrer gerações superpostas (Veloso et al., 2000). Além disso, algumas espécies possuem elevado potencial biótico, o que as torna dominantes em sua área de ocorrência (CANAL, 1997), causando grandes prejuízos à fruticultura local e levando o produtor a utilizar-se do controle químico.

Tradicionalmente, o controle das moscas-das-frutas tem sido feito por meio de iscas tóxicas composta de proteína hidrolisada associada a um inseticida e também pelouso de produtos químicos aplicados em cobertura (CARVALHO, 2004). No entanto, diante das exigências do mercado consumidor, os produtores têm adotado uma série de medidas que visam à redução do controle químico, tais como: práticas de cultivo, monitoramento dos pomares, ensacamento dos frutos e utilização de inimigos naturais, sejam liberando massalmente ou preservando-os por meio da utilização de produtos químicos seletivos e/ou alternativos, tais como os botânicos (LEMos et al., 2002). Os programas de manejo integrado de pragas têm incentivado o uso de todas estas medidas, principalmente a do uso de inimigos naturais e de técnicas que favoreçam o aumento de suas populações, minimizando, desta forma, o desequilíbrio ecológico verificado nos agroecossistemas (ALvARENGA et al., 2006). Estas ações conjuntas poderiam levar a uma redução no uso de agroquímicos convencionais pelos agricultores, diminuindo desta forma, a contaminação do meio ambiente e aumentando a qualidade dos frutos produzidosea sua competitividadenomercado.

Levando-se em consideração que nenhuma das estratégias de manejo deva ser utilizada isoladamente no controle de tefritídeos, esta pesquisa visou avaliar a ação do inseticida botânico nim em larvas de Ceratitis capitata (WIEDEMANN, 1824), bem como no parasitismo destas larvas por Diachasmimorpha longicaudata (ASHMEAD, 1905).

\section{MATERIALEMÉTODOS}

A pesquisa foi desenvolvida no Laboratório de Criação de Insetos da Universidade Estadual de Montes
Claros(UNIMONTES), CampusdeJanaúba,MG. Inicialmente foram construídas "unidades de parasitismo", que simulavam os frutos infestados por moscas-dasfrutas. As unidades foram confeccionadas a partir de um tecido fino do tipo "voil", que foi utilizado para envolver um lote de 100 larvas nuas de C. capitata.

As "unidades de parasitismo", contendo as larvas de C. capitata, foram mergulhadas uma única vez por 30 segundos em uma solução denim, nas concentrações de $0,5 \%, 1 \%$ e 1,5\% do produto comercial "Organic Neem ${ }^{\circledR \prime}$, composto de óleo de nim a 0,37\% (3.686 ppm). Na testemunha as "unidades de parasitismo" foram mergulhadas apenas em água destilada. Após a exposição das "unidades de parasitismo" nas soluções-tratamento, elas foram colocadas para secar por 5 minutos, antes de serem oferecidas ao parasitoide $D$. longicaudata.

Em seguida, as unidades foram colocadas em gaiolas confeccionadas a partir de potes modelo turquesa de $2.200 \mathrm{~mL}$, contendo 10 fêmeas e três machos do parasitoide, que foram dispostas casualmente em uma estante deaço sob condições controladas $\left(26 \pm 1^{\circ} \mathrm{C}\right.$, $65 \pm 10 \%$ de UR e fotofase de $14 \mathrm{~h}$ ).

Realizaram-se dois tipos de experimento, com e sem livre chance de escolha.

Noexperimento sem chance de escolha, uma única "unidade de parasitismo", por tratamento, foi pendurada no interior da gaiola e exposta ao parasitismo por D. longicaudata, por um períodode 2 horase 30 minutos. Esse procedimento foi repetido durante três dias consecutivos, ocasião em que os adultos do parasitoide estavam com 10, 11 e 12 dias após a emergência, pois, segundo Sugayama (2000), D. longicaudata atinge a máxima capacidade de parasitismo no período compreendido entre quatro e 13 dias de idade.

Para verificar a ação isolada do inseticida botânico nim sobre as larvas de C. capitata, um lote destas foi sensibilizado nas soluções-tratamento, não sendo, entretanto, submetido ao parasitismo.

Finalizado o tempo de exposição, as larvas contidas em cada "unidade de parasitismo" foram transferidas para copos descartáveis contendo vermiculita. Esses copos foram fechados com "voil" e presos com elástico, sendo em seguida acondicionados na BOD regulada a $27 \pm 1^{\circ} \mathrm{C}$, umidade relativa de $60 \pm 10 \%$ e fotofase de 14 horas. Diariamente, foi verificada a emergência de parasitoidese/ou moscas.

$\mathrm{O}$ delineamento experimental foi inteiramente casualizadoeconstoude quatrotratamentos (concentração das soluções denim mais uma testemunha) com seis repetições cada, sendo que cada parcela foi constituída porumagaiolacontendouma "unidadedeparasitismo" exposta a uma determinada solução-tratamento.

Avaliou-se a atratividade das larvas de C. capitata ao parasitoide, o número de fêmeas do parasitóide que ovipositaram, onúmero de parasitoides e moscas 
emergidos e oíndice de parasitismo(IP). Para avaliar aatratividadee onúmerodefêmeasqueovipositaram, foi realizada a contagem por gaiola, respectivamente, donúmero de fêmeas que apenas visitaram a "unidade de parasitismo" e daquelas que introduziram o ovipositornas larvas pelo menos uma vez, no período de uma hora. Oíndice de parasitismo (IP) foi calculado conforme Matrangolo et al. (1998) e CarvalHo (2003): IP $=\left[\left(n^{\circ}\right.\right.$ parasitoides emergidos $) /\left(n^{\circ}\right.$ de moscas emergidas $+\mathrm{n}^{\circ}$ parasitoides emergidos) $] \times 100$.

No experimento com chance de escolha, quatro "unidades de parasitismo" foram penduradas no interior de cada gaiola, de forma que os parasitoides, os quais estavam com 5 dias de idade, tivessem livre acesso a todas as unidades tratamentos. Dessa forma, esse experimento constou de quatro tratamentos com seis repetições, sendo que cada parcela foi constituída por uma gaiola contendo quatro "unidades de parasitismo" submetidas aos diferentes tratamentos. Deforma semelhanteaoexperimento sem livrechance de escolha, após a exposição das "unidades de parasitismo" ao parasitoide, as larvas de $C$. capitata foram transferidas para copos descartáveis contendo vermiculita. Os copos foram fechados com "voil" e presos com elástico, sendo em seguida acondicionados em BOD com condições controladas, semelhantes ao experimento anterior. Diariamente, foi verificada a emergência de parasitoides e/ou moscas.

$\mathrm{O}$ delineamento experimental foi inteiramente casualizadoeforamavaliadosonúmerodeparasitoides e moscas emergidos e o índice de parasitismo (IP) (conforme descrito no teste sem livre escolha).

Todos os resultados foram submetidos à análise de variância e ao teste de Tukey a $5 \%$ de probabilidade, por meio do programa estatístico Sisvar (FERREIRA, 2000), sendo que, quando necessário, foram transformados por $\sqrt{x+0,5}$.

\section{RESULTADOSEDISCUSSÃO}

\section{Teste sem livre chance de escolha}

O contato prévio de larvas de C. capitata com soluções com diferentes concentrações de nim não afetou significativamente a atração de fêmeas com 10 dias de idade do parasitoide $D$. longicaudata, em relação à testemunha, a exceção daquelas que foram expostas às concentrações de $1,5 \% \mathrm{e} 1,0 \%$ e oferecidas aos parasitoides com 11 e 12 dias de idade, respectivamente (Tabela 1). Apesar de não ter havido efeito significativo do nim sobre o parasitoide em todos os tratamentos, constatou-se uma reduçãononúmero de fêmeas atraídas quando as larvas foram mergulhadas na suspensão contendo nim. Esta redução pode estar relacionada à ocorrência de repelência do inse- ticida botânico ao parasitoide. Observa-se, ainda, uma diferença na atratividade de fêmeas dos parasitoides que estavam com 10 dias daqueles que estavam com 11 e 12 dias de idade. Esse aumento na atração à "unidade de parasitismo" da testemunha, em relação as demais idades, foi de cerca de 1,6 vezes (166,7\% e $155,7 \%$ para 11 e 12 dias, respectivamente).

O contato prévio de larvas da mosca-das-frutas com soluções de diferentes concentrações denim também não afetou significativamente o parasitismo de fêmeas doparasitoidecom 10 dias deidade, em relação à testemunha, a exceção daquelas que foram expostas às concentrações de 1,0\% e 1,5\% do produto comercial e oferecidas aos parasitoides com 11 e12 dias deidade, respectivamente(Tabela2). Assim, a repelência donim aos parasitoides, constatada quando se avaliou a atratividade dasfêmeas, também afetou o parasitismo (Tabela 1). De forma semelhante ao ocorrido na atratividade (Tabela 1), um menor número de fêmeas com 10 dias de idade parasitou larvas de moscas-dasfrutas, em relaçãoàquelas queestavam com $11 \mathrm{e} 12$ dias de idade (Tabela 2). Comparando o parasitismo realizado por fêmeas com 11 e 12 dias de idade, verifica-se que houve uma redução na oviposição em larvas submetidas à concentração 1,5\% do produto comercial quando comparado com a testemunha.

Tabela1-Númerodefêmeas deDiachasmimorphalongicaudata atraídas às larvas de Ceratitis capitata submetidas previamente ao contato de diferentes concentrações de nim ${ }^{1}$.

Concentrações de Idade do parasitoide (dias) $\operatorname{nim}(\%)$

\begin{tabular}{llll}
\cline { 2 - 4 } & 10 & 11 & 12 \\
\hline Testemunha & $3,00 \mathrm{a}$ & $8,00 \mathrm{a}$ & $7,67 \mathrm{a}$ \\
0,50 & $2,33 \mathrm{a}$ & $4,50 \mathrm{ab}$ & $4,00 \mathrm{ab}$ \\
1,00 & $1,83 \mathrm{a}$ & $4,50 \mathrm{ab}$ & $3,17 \mathrm{~b}$ \\
1,50 & $1,33 \mathrm{a}$ & $2,00 \mathrm{~b}$ & $3,83 \mathrm{ab}$ \\
\hline
\end{tabular}

${ }^{1}$ Médias seguidas pela mesma letra na coluna não diferem entre si pelo teste de Tukey no nível de 5\% de significância.

Tabela2-Númerodefêmeas deDiachasmimorphalongicaudata que parasitaram larvas de Ceratitis capitata submetidas previamente ao contato de diferentes concentrações de nim ${ }^{1}$.

\begin{tabular}{lccc}
\hline $\begin{array}{l}\text { Concentrações de } \\
\text { nim (\%) }\end{array}$ & \multicolumn{3}{c}{ Idade do parasitoide (dias) } \\
\cline { 2 - 4 } & 10 & 11 & 12 \\
\hline Testemunha & $2,83 \mathrm{a}$ & $7,17 \mathrm{a}$ & $7,67 \mathrm{a}$ \\
0,50 & $2,33 \mathrm{a}$ & $4,33 \mathrm{ab}$ & $4,00 \mathrm{ab}$ \\
1,00 & $1,67 \mathrm{a}$ & $3,83 \mathrm{ab}$ & $3,00 \mathrm{~b}$ \\
1,50 & $1,17 \mathrm{a}$ & $2,00 \mathrm{~b}$ & $3,00 \mathrm{~b}$
\end{tabular}

${ }^{1}$ Médias seguidas pela mesma letra na coluna não diferem entre si pelo teste de Tukey no nível de 5\% de significância. 
Tabela 3 - Número de parasitoides Diachasmimorpha longicaudata e de adultos de Ceratitis capitata emergidos, provenientes de larvas submetidas previamente ao contato de diferentes concentrações de nim e expostas ao parasitismo ${ }^{1}$.

\begin{tabular}{ccccccr}
\hline Concentrações de nim (\%) & \multicolumn{5}{c}{ Idade do parasitoide (dias) } \\
\hline & \multicolumn{2}{c}{10} & \multicolumn{2}{c}{11} & \multicolumn{1}{c}{12} \\
\cline { 2 - 7 } & Parasitoide & Moscas & Parasitoide & Moscas & Parasitoide & Moscas \\
\hline Testemunha & $45,25 \mathrm{a}$ & $37,50 \mathrm{a}$ & $47,25 \mathrm{a}$ & $5,25 \mathrm{a}$ & $42,80 \mathrm{a}$ & $2,50 \mathrm{a}$ \\
0,50 & $44,00 \mathrm{a}$ & $64,75 \mathrm{ab}$ & $39,25 \mathrm{a}$ & $11,50 \mathrm{ab}$ & $46,60 \mathrm{a}$ & $11,25 \mathrm{a}$ \\
1,00 & $38,75 \mathrm{a}$ & $44,25 \mathrm{a}$ & $37,75 \mathrm{a}$ & $19,00 \mathrm{~b}$ & $32,40 \mathrm{ab}$ & $37,25 \mathrm{~b}$ \\
1,50 & $25,33 \mathrm{a}$ & $78,75 \mathrm{~b}$ & $25,25 \mathrm{~b}$ & $47,00 \mathrm{c}$ & $22,20 \mathrm{~b}$ & $50,25 \mathrm{c}$ \\
\hline
\end{tabular}

${ }^{1}$ Médias seguidas pela mesma letra na coluna não diferem entre si pelo teste de Tukey no nível de 5\% de significância.

A emergência de parasitoides foi significativamente afetada quando eles estavam com 11 e 12 dias de idade (Tabela 3). Esse efeito pôde ser constatado quando as larvas de C. capitata foram previamente mergulhadas na concentração $1,5 \%$, havendo redução na emergência do parasitoide de $46,5 \%$ e $48 \%$ em relação à testemunha, quando estavam, respectivamente, com 11 e 12 dias.

Aemergênciademoscasesteverelacionadaàconcentração de nim nos tratamentos, ou seja, quanto maior foi aproporçãodenimnaqualaslarvasforammergulhadas, maior a emergência de adultos de $C$. capitata (Tabela 3). Essa maior emergência de moscas nos tratamentos com maioresconcentrações denimsedeve, provavelmente, a ação repelente do inseticida botânico ao parasitoideque, por conseguinte, causou um menor parasitismo das larvas da mosca. A diferença entre a testemunha e o tratamentodemaiorconcentração, quandoasfêmeas do parasitoide estavam com 11 e 12 dias, foi altamente significativa havendo, respectivamente, um acréscimo na emergência de moscas em torno de 8 e 19 vezes.

Com relação à ação isolada do nim sobre as larvas de C. capitata, a exposição destas às soluções-tratamento com diferentes concentrações de nim não afetou significativamentea emergência da mosca (Fig.1). Ocorreram praticamente $100 \%$ deemergência desses insetos. Entretanto, quando se compara com a emergência de moscas cujas larvas foram parasitadas, observa-se uma redução no número de moscas emergidas (Tabela 3).

O índice de parasitismo de D. longicaudata foi negativamente afetado pelo nim quando as larvas de terceiro ínstar de C. capitata foram previamente mergulhadas nas concentrações mais elevadas do inseticida botânico (Fig. 2). Porém, esse efeito nocivo foi constatado apenas quando as fêmeas do parasitoide estavam com 11 e 12 dias de idade. As fêmeas com 12 dias deidade apresentaram umíndice de parasitismo significativamente menor quando parasitaram larvas expostas às concentrações de 1,0\% e 1,5\% denim. Já para aquelas que estavam com 11 dias de idade, esse efeito foi demonstrado somente na concentração
1,5\%, constatando-se uma redução de $67,5 \%$ no índice de parasitismo, em relação à testemunha. Para fêmeas com 12 dias deidade, as reduções no índice de parasitismo foram de $48,9 \%$, para a concentração de $1,0 \%$ e de $64,2 \%$, para a de $1,5 \%$.

\section{Teste com livre chance de escolha}

No experimento em que os parasitoides tiveram livre escolha das "unidades de parasitismo" a sua emergência foi significativamente afetada (Fig. 3). Esse efeito pôde ser constatado quando as larvas de C. capitata foram previamente mergulhas nas concentrações de $1,0 \%$ e $1,5 \%$ de nim, reduzindo $74 \%$ e $61 \%$ a emergência do parasitoide, respectivamente, em relação à testemunha. A baixa emergência de parasitoides delarvas que não foram expostas ao nim (testemunha) pode ser explicada pela presença do odor do produto dentro da gaiola, dificultando com que $D$. longicaudata encontrasse as "unidades de parasitismo" e concretizasse o parasitismo.

A emergência de moscas, provenientes de larvas expostas às diferentes concentrações de nim e posteriormente parasitadas, não foi afetada negativamente (Fig.3), demonstrandooefeito de repelência donimao parasitoide e o não efeito à mosca.

Neste caso, o índice de parasitismo também foi negativamente afetado pela exposição de larvas da mosca ao nim (Fig. 4). Esse efeito foi constatado quando as larvas de $C$. capitata foram mergulhas nas soluções de concentração 1,0\% e 1,5\%, enquanto no tratamento $0,5 \%$ e testemunha o efeito não foi verificado, ocorrendo uma tendência de aumento no índice de parasitismo na concentração de $0,5 \%$.

A partirdos resultadosobtidos, baseadono testesem livre chance de escolha, pode-se observar que as fêmeas de $D$. longicaudata em relação à atratividade e ao ato de parasitarsofreramefeitonegativono primeiromomento (dia) de parasitismo. Este fato está relacionadoà adaptabilidade às gaiolas experimentais utilizadas e de certa forma ao odor do nim. Essa explicação parece ter lógica, jáqueosmesmosparasitoidespermaneceramnasgaiolas 
durante três dias consecutivos, estando eles com 11 e 12 dias (no segundo e terceiro dia de avaliação), havendo tempo para que se adaptassem tanto a gaiola como ao odordenimprovenientedas "unidades deparasitismo". Isto foi constatado pelo fato de um maior número de fêmeaster sidoatraída erealizado posturasnaslarvas da mosca. Essa adaptabilidade às gaiolas e ao odor não impediu, no entanto, que ocorresse uma repelência do nimaoparasitoide $D$. longicaudata, verificada quandoeles estavam com 11 e 12 dias de idade.

A emergência de moscas foi diretamente proporcional ao aumento na concentração de nim e inversamente ao número de fêmeas de $D$. longicaudata que efetuaram o parasitismo. Isso também pode estar relacionadoà repelência do nim ao parasitóide, já que a ocorrência de um menor índice de parasitismo nos tratamentos de maiores concentrações de nim pode ter favorecido o desenvolvimento das larvas, eviden- ciando, desta forma, que o inseticida botânico, nas concentrações utilizadas, não foi prejudicial, por contato, às larvas de $C$. capitata. A baixa quantidade de azadiractina no produto à base de nim utilizado nos experimentos pode ter contribuído para a não ação de contato sobre C. capitata, já que esta substância é o princípio ativo mais importante do ponto de vista entomológico (JACOBSON, 1989). Outra explicação pode ser o fato da azadiractina não agir por contato com larvas da mosca, pois, segundo Ciociola Junior; MARTinez (2002), esta substância é mais efetiva por ingestão do que por contato. Neste experimento as larvas de C. capitata foram somente mergulhadas nas soluções denim, nãoingerindoo produto. Resultados de pesquisas comprovaram os efeitos prejudiciais em adultos de moscas-das-frutas quando estas se alimentaram com compostos à base de nim (Di Ilioet al., 1999; SALES; ReCH, 1999; SingH, 2003).

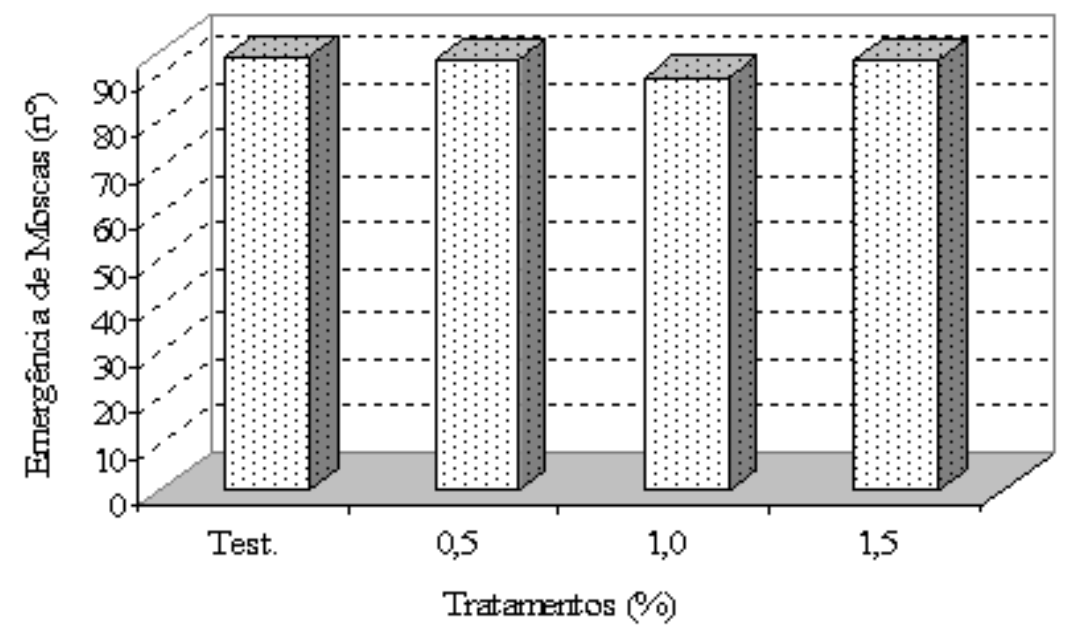

Fig. 1 - Emergência de adultos de Ceratitis capitata cujas larvas foram submetidas previamente ao contato de diferentes concentrações de nim.

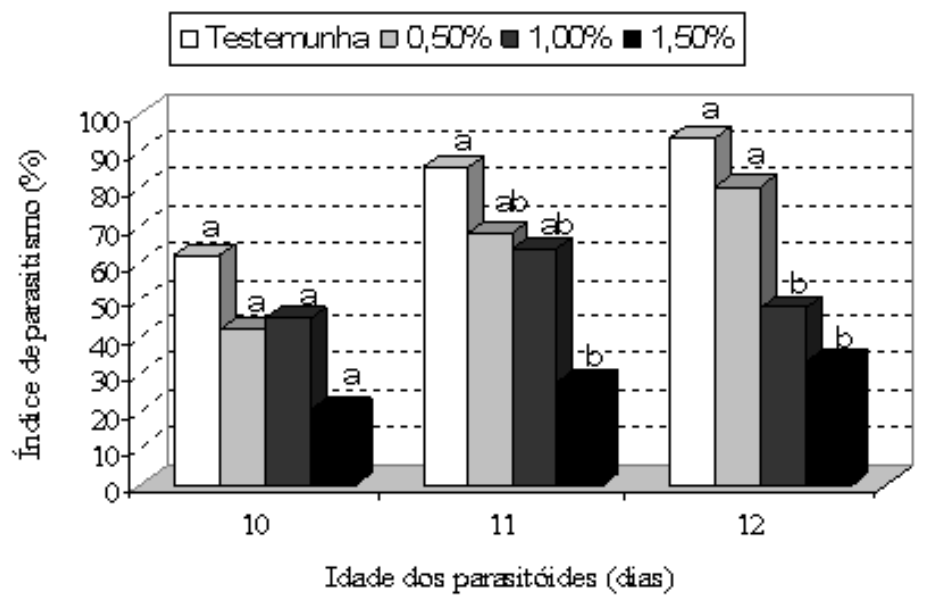

Fig. 2 - Índice de parasitismo por Diachasmimorpha longicaudata em larvas de Ceratitis capitata submetidas previamente ao contato de diferentes concentrações de nim. Médias seguidas pela mesma letra na mesma idade não diferem entre si pelo teste de Tukey no nível de 5\% de significância. 


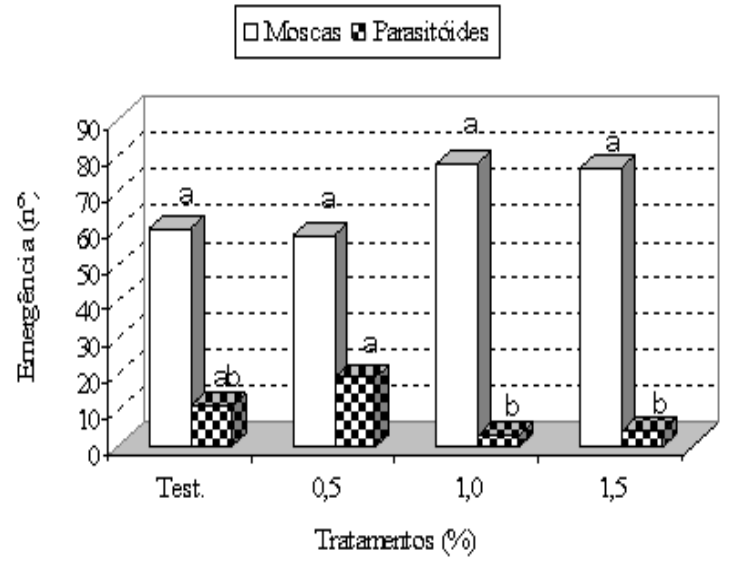

Fig. 3 - Emergência de moscas e parasitoides de larvas de Ceratitis capitata submetidas previamente ao contato de diferentes concentrações de nim e expostas por livre escolha ao parasitismo de Diachasmimorpha longicaudata. Médias seguidas pela mesma letra em cada espécie não diferem entre si pelo teste de Tukey no nível de 5\% de significância.

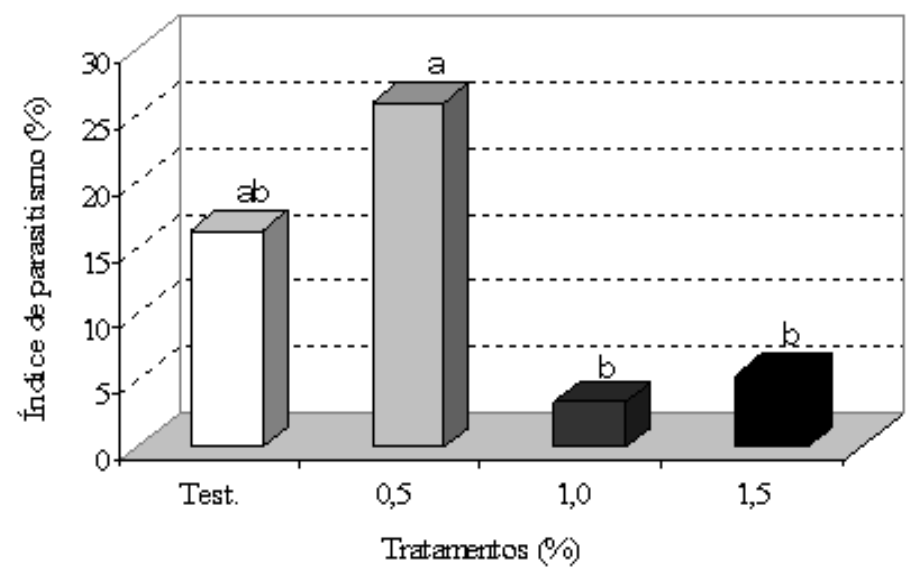

Fig. 4 - Índice de parasitismo por Diachasmimorpha longicaudata em larvas de Ceratitis capitata submetidas previamente ao contato de diferentes concentrações de nim e expostas ao parasitismo por livre escolha. Médias seguidas pela mesma letra não diferem entre si pelo teste de Tukey no nível de 5\% de significância.

Em se tratando do terceironível trófico, o efeito do nim foi mais evidente. No teste com livre escolha a emergência e, consequentemente, o índice de parasitismotenderama serem maioresnotratamentoquando as larvas foram mergulhadas na solução de menor concentração $(0,5 \%)$, sugerindo que esse parasitoide pode apresentar insensibilidade a essa concentração doinseticidabotânico.Comissopodem sedesenvolver normalmente em moscas tratadas previamente ao parasitismo, em concentrações próximas a essa, pois, apesar de não afetarem diretamente a emergência de moscas, possivelmente pode ter sido favorável a atuação do parasitoide. STARK et al. (1992) também observaram maior emergência do parasitoide de moscas-dasfrutas D. tryoni (Cameron) originadas de larvas de $C$. capitata expostas a $10 \mathrm{ppm}$ de azadiractina quando comparadoà testemunha (sem azadiractina) e, segun- do os mesmos autores, a azadiractina, de maneira desconhecida, pode ser benéfica ao desenvolvimento desse parasitoide. De acordo com FOERSTER (2002), as alterações nos processos fisiológicos dos insetos-praga provocadas por efeitos subletais podem ser favoráveis à atuação dos parasitoides, pelo enfraquecimento do hospedeiro, podendo ser esta a explicação de uma maior emergência de parasitoides no tratamento com $0,5 \%$ de nim. Segundo este mesmo autor, verifica-se também que, sobre o tipo de reação de predadores e parasitoides à subdosagens de inseticidas, uma parte significativa dos resultados encontrados na literatura aponta para um incremento no desempenho de inimigos naturais diante de doses subprejudiciais.

No teste com livre chance de escolha, o efeito repelente do nim ao $D$. longicaudata foi verificado nitidamente nas duas maiores concentrações, já que 
a não preferência dos parasitoides às larvas de $C$. capitata tratadas nessas concentrações veio afetar negativamente o número de parasitoides emergidos e o índice de parasitismo.

Um fator a ser considerado é que, em condições de campo, possivelmente a seletividade ao parasitóide poderá ser maximizada, já que, segundo MARTiNEZ (2002), a azadiractina é suscetível à fotodecomposição e se decompõe após 4 horas de exposição à luz solar, reduzindo sua atividade em quase $60 \%$, e também apresenta o período de efeito residual curto( 2 a 7 dias).

Os resultados deste e de outros estudos mostram que a utilização de compostos à base de nim em programas demanejo integrado de pragas poderá ser promissor, no entanto, há necessidade de mais pesquisas com relação à ação no terceiro nível trófico em condições de campo.

\section{CONCLUSÕES}

O óleo de nim, nas concentrações testadas, possui ação de repelência sobre oparasitoide Diachasmimorpha longicaudata e não apresenta efeito prejudicial por contato sobre as larvas de Ceratitis capitata, não afetando a emergência de adultos.

O nim reduz o índice de parasitismo por $D$. longicaudata em larvas de C. capitata.

\section{AGRADECIMENTOS}

À Fundação de Amparo à Pesquisa de Minas Gerais (FAPEMIG) pelo apoio financeiro à pesquisa e pelas bolsas de estudos concedidas aos autores (Mestrado, Iniciação científica e BIPDT).

Aoprofessor JoséErmelino Alves Damasceno pelo apoio nas análises estatísticas.

\section{REFERÊNCIAS}

ALVARENGA, C.D.; GIUSTOLIN, T.A.; QUERINO, R.B. Alternativas no controle de moscas-das-frutas. In: VENZON, M.; PAULA JÚNIOR, T.J. de; PALLINI, A. (Coord.). Tecnologias alternativas para o controle de pragas e doenças. Viçosa: EPAMIG, 2006. p.227-252.

BITTENCOURT, M.A.L.; COVA, A.K.W.; SILVA, A.C.M.; SILVA, V.E.S.; BOMFIM, Z.V.; ARAÚJO, E.L.; SOUZA FILHO, M.F. Espécies de moscas-das-frutas (Tephritidae) obtidas em armadilhas McPhail no Estado da Bahia, Brasil. Semina. Ciências Agrárias, v.27, n.4, p.561-564, 2006.

CANAL, N.A. Levantamento, flutuação populacional e análise faunística das espécies de moscas-das-frutas (Dip.,
Tephritidae) em quatro municípios do norte do Estado de Minas Gerais. 1997. 113p. Tese (Doutorado) - Escola Superior de Agricultura "Luiz de Queiroz", Universidade de São Paulo, Piracicaba, 1997.

CARVALHO, R.S. Estudos de laboratório e de campo com o parasitóide exótico Diachasmimorpha longicaudata Ashmead (Hymenoptera: Braconidae) no Brasil. 2003. 182p. Tese (Doutorado), Instituto de Biociências, Universidade de São Paulo, São Paulo, 2003.

CARVALHO, R.S. Monitoramento de parasitóides nativos e de tefritídeos antes da liberação de Diachasmimorpha longicaudata (Hymenoptera: Braconidae) no submédio São Francisco. Cruz das Almas: Embrapa, 2004. 6p. (Boletim Técnico, 100).

CIOCIOLA JUNIOR, A.I.; MARTINEZ, S.S. Nim: alternativa no controle de pragas e doenças. Belo Horizonte: EPAMIG, 2002. 24p. (Boletim Técnico, n.67).

DI ILIO, V.; CRISTOFARO, M.; MARCHINI, D.; NOBILI, P.; DALLAI, R. Effects of a neem compound on the fecundity and longevity of Ceratitis capitata (Diptera: Tephritidae). Journal Economic of Entomology, v.92, n.1, p.76-82, 1999.

FERREIRA, D.F. Manual do sistema Sisvar para análises estatísticas. Lavras: Universidade Federal de Lavras, 2000. 66p.

FOERSTER, L.A. Seletividade de inseticidas a predadores e parasitóides. In: PARRA, J.R.P.; BOTELHO, P.S.M.; CORRÊA-FERREIRA, B.S.; BENTO, J.M.S. (Ed.) Controle biológico no Brasil: parasitóides e predadores. São Paulo: Manole, 2002. p.95-114.

HICKEL, E.R. Espessura da polpa como condicionante do parasitismo de moscas-das-frutas (DIPTERA: TEPHRITIDAE) por Hymnoptera: Braconidae. Ciência Rural, v.32, n.6, p.1005-1009, 2002.

JACOBSON, M. Botanical Pesticides: past, present and future. In: ARNASON, J. T.; PHILOGENE, B. J. R.; MORAND, P. (Ed.). Inseticides of plant origin. Washington: ACS, 1989. p.1-7.

LEMOS, R.N.S.; SILVA, C.M.C.; ARAÚJO, J.R.G.; COSTA, L.J.M.P.; SALLES, J.R.J. Eficiência de substâncias atrativas na captura de moscas-das-frutas (Diptera: Tephritidae) em goiabeiras no município de ItapecuruMirim (MA). Revista Brasileira de Fruticultura, v.24, n.3, p.687-689, 2002.

MARTINEZ, S.S. O Nim - Azadirachta indica: natureza, usos múltiplos, produção. Londrina: IAPAR, 2002. $142 \mathrm{p}$.

MATRANGOLO, W.J.R.; NASCIMENTO, A.S.; CARVALHO, R.S.; MELO, E.D.; JESUS, M. de Parasitóides de moscas-das-frutas (Diptera: Tephritidae) associados a 
fruteiras tropicais. Anais da Sociedade Entomológica do Brasil, v.27, n.4, p.593-603, 1998.

NASCIMENTO, A.S.; CARVALHO, R.S. Manejo integrado de moscas-das-frutas. In: MALAVASI, A.; ZUCCHI, R.A. (Ed.). Moscas-das-frutas de importância econômica no Brasil: conhecimento básico e aplicado. Ribeirão Preto: Holos, 2000. p.169-173.

NORA, I.; HICKEL, E.R.; PRANDO, H.F. Moscas-dasfrutas nos Estados Brasileiros: Santa Catarina. In: MALAVASI, A.; ZUCCHI, R.A. (Ed.). Moscas-das-frutas de importância econômica no Brasil: conhecimento básico e aplicado. Ribeirão Preto: Holos, 2000. p.271-275.

SALLES, L.A.; RECH, N.L. Efeito de extratos de nim (Azadiractha indica) e cinamomo (Melia azedarach) sobre Anastrepha fraterculus (Wied.) (Diptera: Tephritidae). Revista Brasileira de Agrociência, v.5, n.3, p.225-227, 1999.

SINGH, S. Effects of aqueous extract of neem seed kernel and azadirachtin on the fecundity, fertility and post-embryonic development of the melonfly, Bactrocera cucurbitae and the oriental fruit fly, Bactrocera dorsalis (Diptera: Tephritidae). Journal of Applied Entomology, v.127, p.540-547, 2003.

STARK, J.D.; WONG, T.T.Y.; VARGAS, R.I.; THALMAN, R.K. Survival, longevity, and reproduction of tephritid fruit fly parasitoids (Hymenoptera: Braconidae) reared from fruit flies exposed to azadirachtin. Journal Economic of Entomology, v.85, n.4, p.1125-1129, 1992.

SUGAYAMA, R.L. Anastrepha fraterculus (Wiedemann) (Diptera: Tephritidae) na região produtora de maças do Rio Grande do Sul: Relação com seus inimigos naturais e potencial para o controle biológico. 2000.117p. Tese (Doutorado) - Instituto de Biociências, Universidade de São Paulo, São Paulo, 2000.

VELOSO, V.R.S.; FERNANDES, P.M.; ZUCCHI, R.A. Goiás. In: MALAVASI, A.; ZUCCHI, R.A. (Ed.). Moscasdas-frutas de importância econômica no Brasil: conhecimento básico e aplicado. Ribeirão Preto: Holos, 2000. p.247-252.

Recebido em 9/5/08

Aceito em 22/10/09 